\title{
Forecasting the North Atlantic Oscillation index using altimetric sea level anomalies
}

\author{
Małgorzata Świerczyńska-Chlaściak ${ }^{1} \cdot$ Tomasz Niedzielski $^{1}$ (D)
}

Received: 12 March 2020 / Accepted: 14 August 2020 / Published online: 27 August 2020

(c) The Author(s) 2020

\begin{abstract}
The objective of this paper is to present a new approach for forecasting NAO index (NAOi) based on predictions of sea level anomalies (SLAs). We utilize significant correlations (Pearson's $r$ up to 0.69 ) between sea surface height (SSH) calculated for the North Atlantic $\left(15-65^{\circ} \mathrm{N}\right.$, basin-wide) and winter Hurrell NAOi, as shown by Esselborn and Eden (Geophys Res Lett 28:3473-3476, 2001). We consider the seasonal and monthly data of Hurrell NAOi, ranging from 1993 to 2017 . Weekly prognoses of SLA are provided by the Prognocean Plus system which uses several data-based models to predict sea level variation. Our experiment consists of three steps: (1) we calculate correlation between the first principal component (PC1) of SSH/SLA data and NAOi, (2) we determine coefficients of a linear regression model which describes the relationship between winter NAOi and PC1 of SLA data (1993-2013), (3) we build two regression models in order to predict winter NAOi (by attaching SLA forecasts and applying coefficients of the fitted regression models). The resulting 3-month prognoses of winter NAOi are found to reveal mean absolute errors of 1.5 or less. The choice of method for preparing SLA data for principal component analysis is shown to have a stronger impact on the prediction performance than the selection of SLA prediction method itself.
\end{abstract}

Keywords North Atlantic Oscillation · Sea level change · Satellite altimetry · Prediction · Autoregressive models

\section{Introduction}

Periodic, short- and medium-term, as well as quickly noticeable changes in ocean level are associated with a number of processes and phenomena occurring in the atmosphere and hydrosphere. Meteorological conditions such as pressure, wind strength and direction, precipitation and evaporation cause irregular and short fluctuations in sea and ocean levels. Because the oceans have an extremely high thermal capacity, when compared to the atmosphere, the ocean temperatures fluctuate seasonally much less than the atmospheric

Tomasz Niedzielski

tomasz.niedzielski@uwr.edu.pl

1 Department of Geoinformatics and Cartography, Faculty of Earth Sciences and Environmental Management, University of Wroclaw, pl. Uniwersytecki 1, 50-137 Wrocław, Poland 
temperature. For the same reason, when air blows over the water, its temperature tends to reach the temperature of the water rather than vice versa. Thus, maritime climates are generally less variable than climates of regions located in the interiors of the continents. The pattern of atmospheric circulation largely determines the pattern of oceanic surface circulation, which in turn determines the location and amount of heat that is released to the atmosphere. Also, the pattern of atmospheric circulation partly determines the location of clouds, which influences the locations of heating of the ocean surface.

One of the most predominant atmospheric phenomenon on the Earth is the North Atlantic Oscillation (NAO) which has been subject of scrutiny over years (e.g. Walker 1924; Bjerknes 1964; Barnston and Livezey 1987; Hurrell 1995; Marshall and Schott 1999; Hurrell et al. 2003). The NAO phenomenon forms a dominant mode of winter climate variability in the North Atlantic region, ranging from central North America to Europe, and extending its impact to northern Asia (Walker and Bliss 1932; Van Loon and Rogers 1978; Rogers and van Loon 1979). The NAO influences cover parts of the East Atlantic and West Atlantic patterns, as originally shown by Wallace and Gutzler (1981) for the winter period on the Northern Hemisphere. The NAO phenomenon consists of balance changes between relatively stable northern and southern atmospheric pressure centers (IPCC 2007). The first one is located over Greenland and called the Icelandic Low (IL), while the second one, known as the Azores High (AH), is located in mid-latitudes of the North Atlantic, i.e. between 35 and $40^{\circ} \mathrm{N}$ (Wanner et al. 2001). Through the fluctuations in the strength of the north-south dipole, NAO controls the strength and direction of westerly winds and storm tracks across the North Atlantic (Feistel et al. 2008). Hence, it is associated with large-scale modulations of the normal patterns of zonal and meridional heat and moisture transport (Hurrell 1995). Walker (1923) first noticed a tendency towards a simultaneous strengthening or weakening of IL and $\mathrm{AH}$, and he named these changes as NAO. The positive (negative) mode of NAO occurs when IL and AH are simultaneously strong (weak). This teleconnection pattern is generally defined as the normalized sea level pressure difference between Ponta Delgada (Azores) and Akureyri (Iceland). It appears in the first eigenvector of sea level pressure field in the Northern Hemisphere (Barnston and Livezey 1987; Rogers 1990), accounting for roughly one third of the variability in sea level pressure over the North Atlantic Ocean (Deser and Blackon 1993).

To quantify the anomalous difference between the polar low and the subtropical high during the boreal winter (DJFM-from December to March), the NAO index (NAOi) was created. The first constructed NAOi involved temperature and pressure data from Europe and North America, and was calculated using a complex and multi-staged statistical procedure (Walker and Bliss 1932). The index reveals interannual variability, but it also has a tendency to persist in one phase over several years. The monthly NAOi is calculated on a basis of decadal sea level pressure measurements performed at two selected meteorological stations. The most popular versions of NAOi are: (1) the Rogers NAO index (between Ponta Delgada (Azores) and Akureyri (Iceland) stations); (2) the Hurrell NAO index (between Lisbon (Portugal) and Stykkishólmur (Iceland) stations); and (3) the Jones NAO index (between Gibraltar and Stykkishólmur stations).

Predictions of NAO are useful for the economy and environment, and therefore several dedicated forecasting methods and services have been developed. Based on the principal components of sea surface temperature (SST) changes, Saunders and Qian (2002) elaborated an empirical model to predict winter NAOi. Eshel (2003) used the North Pacific surface pressure to produce 21-month forecasts of NAO based on various autoregressive models. The Climate Prediction Center of the National Oceanic and Atmospheric Administration (NOAA) provides daily, weekly, 10-day and 14-day forecasts of NAOi 
along with the mean value of NAOi as well as the correlation coefficients between the observations and all the forecasts for last 120 days. The NAOi forecasts are also based on the Global Forecasts System (GFS) and the associated ensemble mean model, produced by the National Centers for Environmental Prediction (NCEP). Yet another institution which provides long-term forecasts of winter NAOi is the European Centre for Medium-Range Weather Forecasts (ECMWF). Its Monthly Forecasting (MOFC) system is based on an ensemble of 51 coupled ocean-atmosphere integrations which produce 32-day forecast every two weeks (Vitart 2004). Recently, Wang et al. (2017) developed a skillful empirical model to predict winter NAO variability, and Dobrynin et al. (2018) utilized a dynamical ensemble model to produce seasonal NAO forecasts.

Most approaches developed to forecast NAOi use predictors like SST, sea level pressure or ocean heat content, however none of them is based on SSH or sea level anomaly (SLA). It is widely known that sea level adjusts to changes in barometric pressure due to the inverted barometer effect (Wunsch and Stammer 1997; Ponte and Gaspar 1999). Sea level response to atmospheric pressure was the topic of several research, e.g. conducted by Garrett (1983), Ducet et al. (1999) and Mathers and Woodworth (2001). The SLA variation reflects changes in atmospheric patterns (Chen et al. 2014; Iglesias et al. 2017), therefore, SLA may be used as an explanatory variable to construct predictions of NAOi.

The correlation between variability of surface ocean topography and NAO phases was discussed by Esselborn and Eden (2001). The first Empirical Orthogonal Function (EOF) component of the observed seasonal SSH anomalies was found to explain $34 \%$ of variance. Pingree (2002) studied the relationship between the NAO index and the SSH along a meridional transect at $35^{\circ} \mathrm{N}$ in the North Atlantic and found vivid, but delayed (one year up) correlations. Investigations into the interannual variability of SSH conducted by Cromwell (2006) led the author to the conclusion that the first principal component of SSH, which is also considered in this paper, is anti-correlated with other commonly used index over North Atlantic-East Atlantic (EA) pattern index. Similarly to Esselborn and Eden (2001), the author applied complex EOF analysis and then used wavelet analysis to determine time-varying spectral density content of the principal components. Other elements of the climate system that may improve predictability of NAO are discussed by Smith et al. (2014).

The main objective of this paper is to use SLA as the input data to issue long-term forecast of NAOi. Herein, we present, verify and validate a new approach for predicting NAOi, which integrates stochastic models implemented within the Prognocean Plus system (Niedzielski and Miziński 2013; Świerczyńska et al. 2016) with the SSH-NAOi relationship presented by Esselborn and Eden (2001). The research hypothesis is the following: "it is possible to skilfully predict NAOi with the 3-month lead time based solely on the prognoses of sea level change".

\section{Data}

Three sets of data are used in this paper: SLA, SSH and winter Hurrell NAOi. The relationship between SLA and SSH is described by the formula:

$$
S L A=S S H-M S S H,
$$

where MSSH is the Mean Sea Surface Height. 
Both SLA (variable "sea_surface_height_above_sea_level") and SSH (variable "sea_ surface_height_above_geoid") datasets were obtained courtesy of the Copernicus Marine Environment Monitoring Service (CMEMS) from the repository called "Global Ocean Gridded L4 Sea Surface Heights and derived variables reprocessed (1993-ongoing)". Both datasets were processed by DUACS (Data Unification Altimeter Combination System) which is a part of the CNES (Centre National d'Etudes Spatiales) multimission ground segment SSALTO (Segment Sol multimissions d'ALTimétrie, d'Orbitographie et de localization précise). It processes data from all available altimetric missions (Jason-3, Sentinel3A, HY-2A, Saral/AltiKa, Cryosat-2, Jason-2, Jason-1, Topex/Poseidon (T/P), ENVISAT, GFO, ERS1/2) and provides a consistent and homogeneous catalogue of products. For the $\mathrm{SSH}$ data a few altimeter corrections and processing algorithms were used so that the data are devoid of: the ionospheric effect, wet and dry troposphere, ocean-, pole- and solid earth tides or the sea state bias. The multimission gridded SLA time series is computed from $\mathrm{SSH}$ referenced to a twenty-year mean.

Spatial resolution of the data is $1 / 4^{\circ} \times 1 / 4^{\circ}$. After Esselborn and Eden (2001), we utilize only gridded SLA and SSH data, spatially limited to $15-65^{\circ} \mathrm{N}$ and $0-80^{\circ} \mathrm{W}$. Due to data availability (the first altimetric satellite T/P was launched in 1992), we consider data collected between 1993 and 2016, aggregated to months (12 per year) and seasons (4 per year).

The monthly and seasonal gridded data where produced by performing simple averaging for each grid of original gridded (multidimensional) time series of SLA/SSH. We created a dataset for each grid (one dimension) that consisted of SLA/SSH values for a winter month or three winter months (season), and calculated the corresponding mean value. We conducted this process for each year.

The monthly and seasonal station-based Hurrell NAOi time series were obtained from Climate Data Guide (Hurrell et al. 2017). For the purpose of this study, we consider only winter months, i.e. December/January/February (D/J/F), and winter seasons (DJF).

\section{Methods}

\subsection{Prognocean Plus}

Prognocean Plus is a real-time system for computing sea level prediction. It is an upgraded version of the Prognocean system described in detail by Niedzielski and Miziński (2013). Prognocean Plus has been developed as a new generation domain-specific service within the PL-Grid infrastructure for Polish science (http://www.plgrid.pl/en, access date: 29/03/2018). By 2018, the system was available through the dedicated real-time online service (https://prognocean.plgrid.pl/, access date: 24/07/2018). Currently, it is not operational. Prognocean Plus produced SLA forecasts based on SLA time series obtained courtesy of CMEMS. The system produced short- (up to 14 days) and long-term (up to 12 weeks) predictions of global altimetric gridded SLA time series, updated daily (Świerczyńska et al. 2016). The spatial resolution of the SLA forecasts was $1 / 4^{\circ} \times 1 / 4^{\circ}$. Along with the prognoses, gridded statistical maps of prediction performance were produced, showing spatial distributions of Mean Absolute Error (MAE) and Root Mean Square Error (RMSE) of forecasts. The Prognocean Plus system was implemented in R (language and environment for statistical computing and graphics) and used the Message Passing Interface (MPI) computations with OpenMPI (https://www.open-mpi.org/, access date: 24/07/2018). 


\subsection{Stochastic models in Prognocean Plus}

The Prognocean Plus system computed the predictions of time-variable ocean topography using data-based methods. The legitimacy of the use of a statistical approach for modelling physical phenomena is widely discussed in the literature (McPhaden et al. 2006; Clark 2008; Sarachik et al. 2010). Moore et al. (2013) constructed the semiempirical global sea level projections, compared them with the process-based projections of SLA, and arrived at the conclusion that statistical and dynamical models have comparable predictive abilities.

The following statistical models were used in the Prognocean Plus system:

- the deterministic polynomial-harmonic model (Polynomial-Harmonic, PH),

- a combination of the PH model and the stochastic autoregressive model (AutoRegressive, AR), briefly called $\mathrm{PH}+\mathrm{AR}$,

- a combination of the PH model with the stochastic threshold autoregressive model (Threshold AutoRegressive, TAR), known as PH+TAR,

- a combination of the PH model and the multivariate autoregressive model (Multivariate AutoRegressive, MAR), briefly called PH+MAR.

The PH model consists of linear trend and five basic non-tidal harmonic oscillations (annual, semi-annual, 120-, 90- and 62-day). These deterministic components can be described as a sum of polynomial or harmonic nonlinear models, the parameters of which can be estimated using the Gauss-Newton algorithm within the weighted least-squares approach. The PH-based predictions are extrapolations of the model. The differences between the observed SLA data and the simulations from the PH model are residuals. They were subsequently modelled with the use of stochastic methods, as described in detail by Niedzielski and Miziński (2013) and Świerczyńska et al. (2016).

The physical background of the PH model with five harmonic components is based on the papers by Kosek (2001), Niedzielski and Kosek (2009) and Kosek et al. (2016) who, using Fourier transform band pass filter, identified the most energetic periodic oscillations in sea level as a function of geographic location. Apart from the annual oscillation, which is associated with the annual cycle and is found to be broadband (Kosek et al. 2016), Kosek (2001) found that semi-annual, 120-, 90- and 62-day components are more energetic in the Northern Hemisphere than in the Southern Hemisphere. In addition, the presence of these oscillations has been identified in sea level variation in the North Atlantic Ocean and some of its seas, mainly in the east-equatorial Atlantic Ocean, the North American Basin, the North Sea and the Baltic Sea (Kosek 2001). Also, the annual oscillation is found to be energetic in parts of the North Atlantic Ocean, as shown for the Caribbean Sea (Niedzielski and Kosek 2009) and the western North Atlantic (Kosek et al. 2016). The 62-day component is an alias-type oscillation driven by observing the M2 and S2 tide waves by altimetric satellites with 10-day sampling interval (Wagner et al. 1994; Kosek 2001). The polynomial component in the PH model has been assumed to be linear because in a short time scale (a few years) there has been no meaningful acceleration in sea level change observed by T/P, Jason-1 and Jason-2 satellites (Niedzielski and Kosek 2011).

The $A R(p)$ solution is widely known in the theory of one-dimensional time series (Brockwell and Davis 2002; Cryer and Chan 2008). Here, the model $Y(t, \varphi, \lambda)$ is fitted to the residuals of SLA data at a given location $(\varphi, \lambda)$ to improve prediction skills, 
especially for a few first prediction steps. The required model parameters are calculated automatically using the Yule-Walker method (Brockwell and Davis 1996). The choice of the order $p$ is based on minimizing the Akaike Information Criterion (AIC) (Akaike 1971). The optimal AR-based linear prediction for $r$ steps into the future is calculated recursively on a basis of the autoregression equation.

The TAR solution is the self-excitive modified version of AR model, which allows to switch between two main equations depending on the randomly determined process in the past. When the threshold is attained, the model is automatically adjusted and the more efficient equation is chosen. Model estimation and calculation of forecasts are carried out in accordance with the procedure described in Cryer and Chan (2008), using the Time Series Analysis (TSA) package in R environment.

The MAR approach is a vector version of the AR model. It is based on cross-correlations within a multivariate time series of SLA (Lardies 1996). Here, the MAR model is implemented in a moving rectangular window (width of 1.25 degrees of longitude and height of 0.75 degrees of latitude), centred in the grid cell where prediction is needed.

\subsection{Relationship between sea level changes and NAO}

The NAO phenomenon reveals interseasonal, interannual (Hurrell 1995; Feldstein 2003; Benedict et al. 2004; Woollings et al. 2015) and even decadal or multidecadal (Stephenson et al. 2000; Visbeck et al. 2001; Bell and Chelliah 2006; Olsen et al. 2012) variability. Bjerknes (1964) described the ocean-atmosphere interactions with respect to North Atlantic climate variability. He stated that heat exchange in the atmosphere and sea surface temperatures play an important role in producing NAO. Based on that, Van Loon and Rogers (1978) found that there exists a significant correlation between atmospheric circulation and sea surface temperature (SST). In addition, many authors have investigated a possible role of Atlantic sea surface temperature anomalies in driving change in the surface pressure patterns resembling NAO (Ratcliffe and Murray 1970; Peng et al. 1997; Czaja and Frankignoul 1999; Rodwell et al. 1999; Rodwell and Folland 2003). Furthermore, Lozier et al. (2008) showed that changes in ocean heat content can be connected to the decadal trend in the NAO signal. The newest research conducted by Yeager et al. (2012) offered the knowledge about feedback between the NAO index and ocean heat content.

It is known that the NAO signal is present in SSH or SLA time series from the North Atlantic region (Cabanes et al. 2006). The methodical bases for quantifying the relationship between SSH and NAOi were proposed by Esselborn and Eden (2001) who utilized the Principal Component Analysis (PCA). It is a statistical procedure that allows us to transform a two-dimensional set of dependent variables to a one-dimensional set of independent variables (principal components) using EOF. The principal components are dominant patterns. The new variables represent the same amount of information as the original variables, and their total variance remains the same. However, it is redistributed among the new variables in the most "unequal" way: the first of them explains not only the majority of variance among the new variables, but also the majority of variance that a single variable can possibly explain (Jolliffe and Cadima 2016).

To perform PCA we used the "prcomp" function (Venables and Ripley 2002; R Development Core Team 2008) from the "stats" package in R environment. The above-mentioned package and the "prcomp" function are commonly used in the environmental studies when there is a need to conduct PCA (Chandler and Scott 2011; Tapolczai et al. 2018; Will and Kitaysky 2018; Al-Karkhi and Alqaraghuli 2019). The calculation is carried out by 
a singular value decomposition (SVD) of the (centred and possibly scaled) data matrix, not by using eigenvalues on the covariance matrix. Unbiased variances are utilized. The use of the SVD method is preferred if numeral accuracy is required.

Esselborn and Eden (2001) used the T/P altimeter SSH data provided by Archiving, Validation and Interpretation of Satellite Oceanographic data (AVISO), spanning the time interval from 1993 to 1998 . The spatial resolution of the data was $1^{\circ} \times 1^{\circ}$, and the authors limited their spatial extent to $15-65^{\circ} \mathrm{N}$ and $0-80^{\circ} \mathrm{W}$. The gridded SSH altimetry data were referenced to the mean seasonal SSH along the satellite tracks to calculate anomalies. The seasonal Hurrel NAOi was used, and therefore in order to unify sampling intervals, the SSH time series was averaged to four seasons per year: December to February (DJF), March to May (MAM), June to August (JJA) and September to November (SON). To compare the seasonal SSH variability with NAOi, the PCA method was used to extract the first principal component of gridded SSH data (PC1SSH) for each season. Esselborn and Eden (2001) extracted only winter Hurrel NAOi values which were subsequently compared with $\mathrm{PC} 1 \mathrm{SSH}$, and the two variables were found to be correlated.

Although Esselborn and Eden (2001) noticed limitations of their approach due to a small number of altimetric observations available at that time, they provided possible explanation of the relationship between SSH and NAO. They presented the reasoning that the NAO-related wind stress curl controls anomalies of ocean circulation and, as a consequence, leads to the interannual changes in heat content of the North Atlantic Ocean.

\subsection{New approach for forecasting NAOi}

In this paper, we explore two methods for preparing input time series to perform PCA and to extract PC1 of SLA/SSH for winter seasons or months. The approaches are graphically presented in Fig. 1. The sketch consists of two parts, where part "a" presents the use of the two methods for seasonal SLA/SSH data, while part "b" corresponds to monthly SLA/ SSH data. The first method, known hereinafter as "method 1", is based on the complete time series of SLA/SSH (all seasons and months), which become input data for PCA. After analysis, the first principal components for winter seasons and months are extracted. The second method, called "method 2", is based on subsets of SLA/SSH time series, in which only winter seasons or winter months are selected to perform PCA.

The procedure of producing the NAOi forecasts is graphically presented in Fig. 2. At least 20 years (1993-2013) of the observed SLA data are needed to fit a linear regression model. We allow four temporal resolutions (Fig. 1), and the resulting time series are processed by "method 1" and "method 2".

In the next step, following Esselborn and Eden (2001), PCA is performed on the observed SLA time series. In "method 1", the calculated PC1s of winter seasons or months must be extracted. Based on the calculated PC1s (4 types) and time series of NAOi (for winter seasons or months only) we can construct a regression model describing the relationship between SLA and NAOi using the following formula:

$$
\text { NAOi }=a \times P C 1 S L A+b,
$$

where NAOi is expressed by the step-adjusted linear regression model describing the Hurrell winter (seasonal or monthly) NAO index, $a$ and $b$ are model coefficients and PC1SLA is time series of one of the four possible sets of principal component time series (PC1SLA computed using "method 1" for seasonal and monthly data-two datasets, and PC1SLA computed using "method 2" for both temporal resolutions-additional two datasets). 

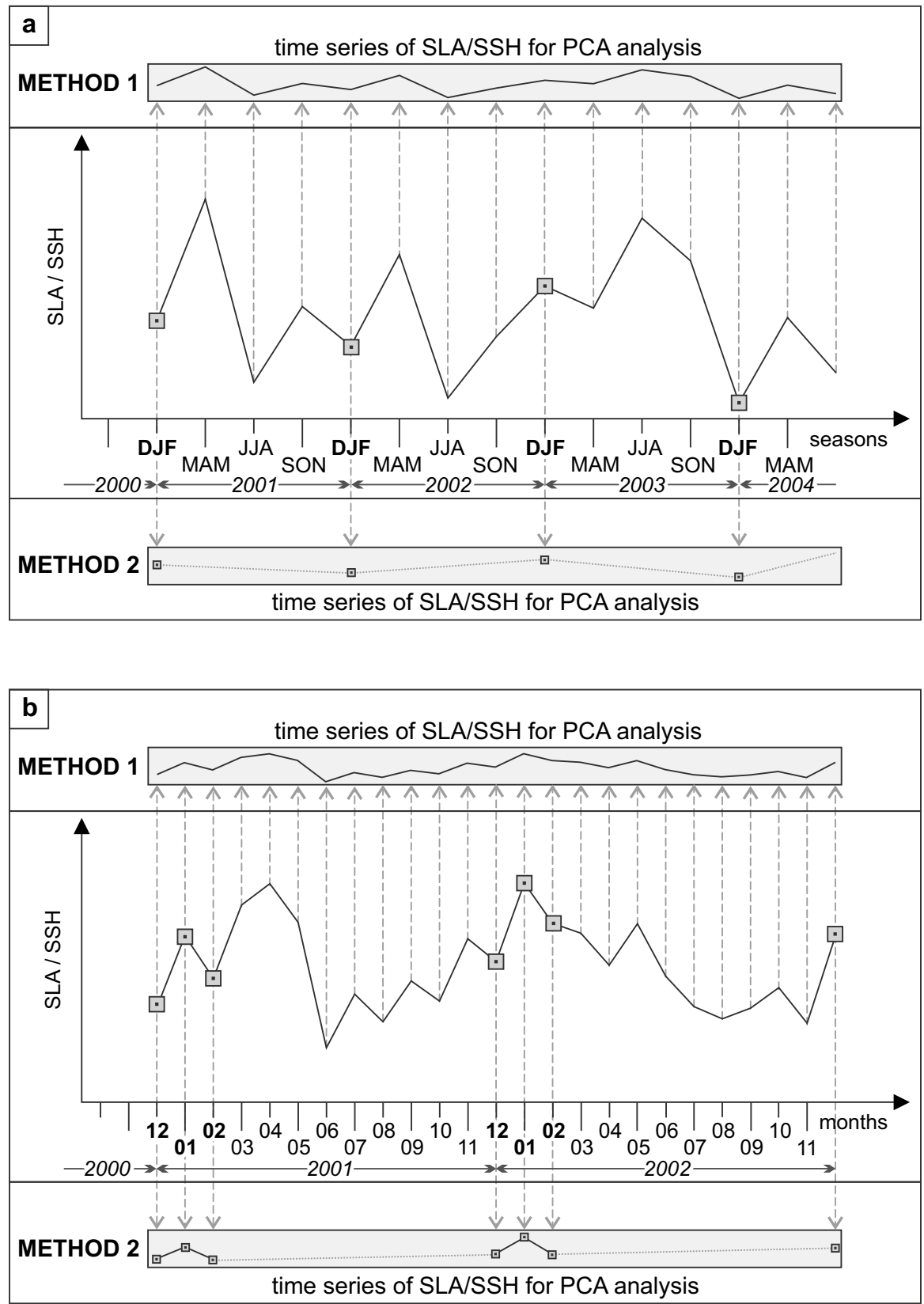

Fig. 1 Scheme of preparing seasonal (part "a") and monthly (part "b") SLA/SSH datasets for PCA using two methods. First method uses complete seasonal or monthly data (respectively 4 gridded map per year and 12 gridded maps per year) as an input data for PCA. After analysis, first principal components for winter seasons/months are extracted. In second method, winter seasons/months are already extracted from SLA/SSH dataset, hence shorter time series are input data for PCA. After analysis, no extraction is needed 


\section{PROCEDURE FOR COMPUTING PROGNOSES OF WINTER HURREL NAO INDEX SOLELY BASED ON THE SEA LEVEL ANOMALY FORECASTS}

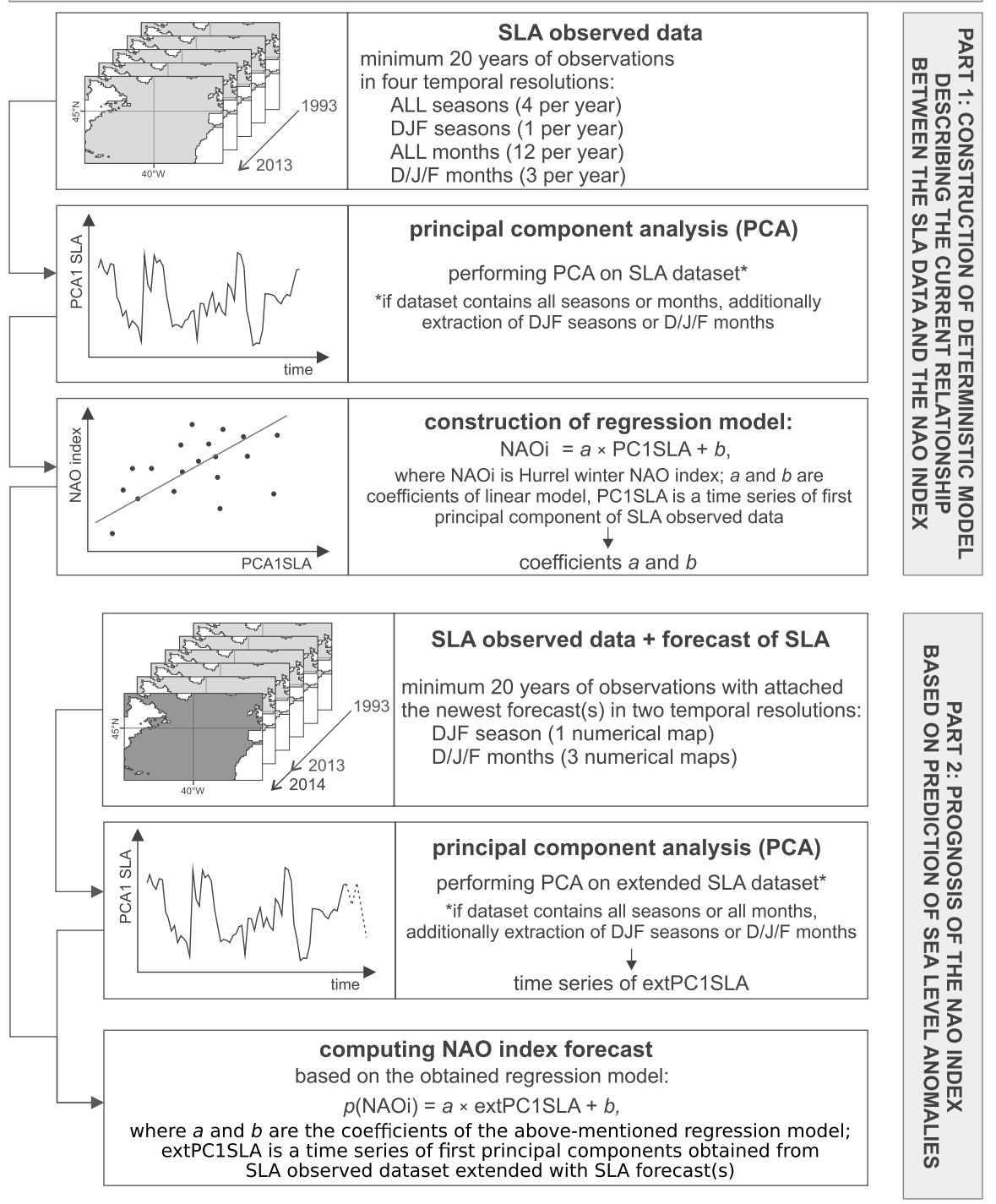

Fig. 2 Scheme presenting several steps in procedure of predicting winter Hurrell NAOi based solely on SLA observed and forecasted data using linear regression model based on time series of PC1SLA

The above-mentioned regression model is recalculated every time, when new prognoses of NAOi are needed. The length of input SLA dataset is equal to the number of the available observations at the time of forecast determination. Hence, a new set of PC1SSH data is produced at every time step. The regression model is necessary to obtain coefficients $a$ and $b$, which are used in the subsequent step of the procedure. 
After fitting the regression model based on the observed SLA time series, we extend this dataset by attaching a newly-predicted SLA gridded map (one map containing SLA prognoses for the next DJF season or three maps consisting of SLA predictions for the next three winter months). Such gridded predictions are computed by the Prognocean Plus system using one of three stochastic models (PH+AR, PH+TAR or PH+MAR). The observed SLA data together with the attached newest gridded forecast, prepared using the above-mentioned methods 1 and 2, becomes input data for PCA. As previously, in the case of "method 2", it is necessary to extract PC1s for winter seasons and months.

The last step of the procedure for computing prognoses of NAOi is the use of the regression model, based on the previously calculated coefficients and the extended time series of PC1SLA, utilizing the formula:

$$
p(N A O i)=a \times \operatorname{extPC1SLA}+b,
$$

where $p(N A O i)$ is the step-adjusted linear regression model predicting Hurrell winter (seasonal or monthly) NAO index, $a$ and $b$ are the already estimated model coefficients obtained to express NAOi, extPC1SLA is a time series composed of one of the four possible sets of principal component data (the same procedure as described above, but with the original time series of SLA extended by attaching the nearest winter prediction). The last component of extPC1SLA is calculated for the predicted gridded SLA data, attached to the observational dataset. In addition to the regression model $p(N A O i)$, we determine its modified version $p^{\prime}(\mathrm{NAO} i)$ produced by applying the empirical correction. It is the $p(N A O i)$ model multiplied by a coefficient defined as a ratio between standard deviation of the NAOi time series and standard deviation of extPC1SLA data, namely:

$$
p^{\prime}(N A O i)=p(N A O i) \times \frac{\sigma_{N A O i}}{\sigma_{e x t P C 1 S L A}},
$$

where $p(N A O i)$ is the step-adjusted linear regression model from the first approach to predict NAOi, $\sigma_{N A O i}$ is standard deviation of NAOi dataset, $\sigma_{\text {extPC } 1 S L A}$ is standard deviation of PC1SLA time series computed based on the observed SLA with attached forecast(s). This procedure results in the same variances of NAOi time series and the NAOi data reconstructed from the $p^{\prime}(N A O i)$ regression model.

\section{Results}

In this study, we carried out two analyses: (1) we performed the calculations along the lines of the paper by Esselborn and Eden (2001) on a basis of SSH and SLA datasets, which allowed us to confirm the strong relationship between NAOi and SSH/SLA for the 20-year time span and to quantify the relation in question; (2) based on the dependency we used the associated regression models along with the real-time SLA predictions computed by the Prognocean Plus system. The approach was used to predict winter NAOi for four boreal winters from $2013 / 2014$ to $2016 / 2017$.

The length of time series included in the analyses varies between 21 and 72, depending on the selected approach, the temporal resolution (seasons vs. months) and the prognosis itself (into which season it hits). The shortest time series is for the prediction of the $2013 / 2014$ season computed using seasonal data. In contrast, the longest time series is utilized for the prediction of the 2016/2017 season calculated using monthly data. 


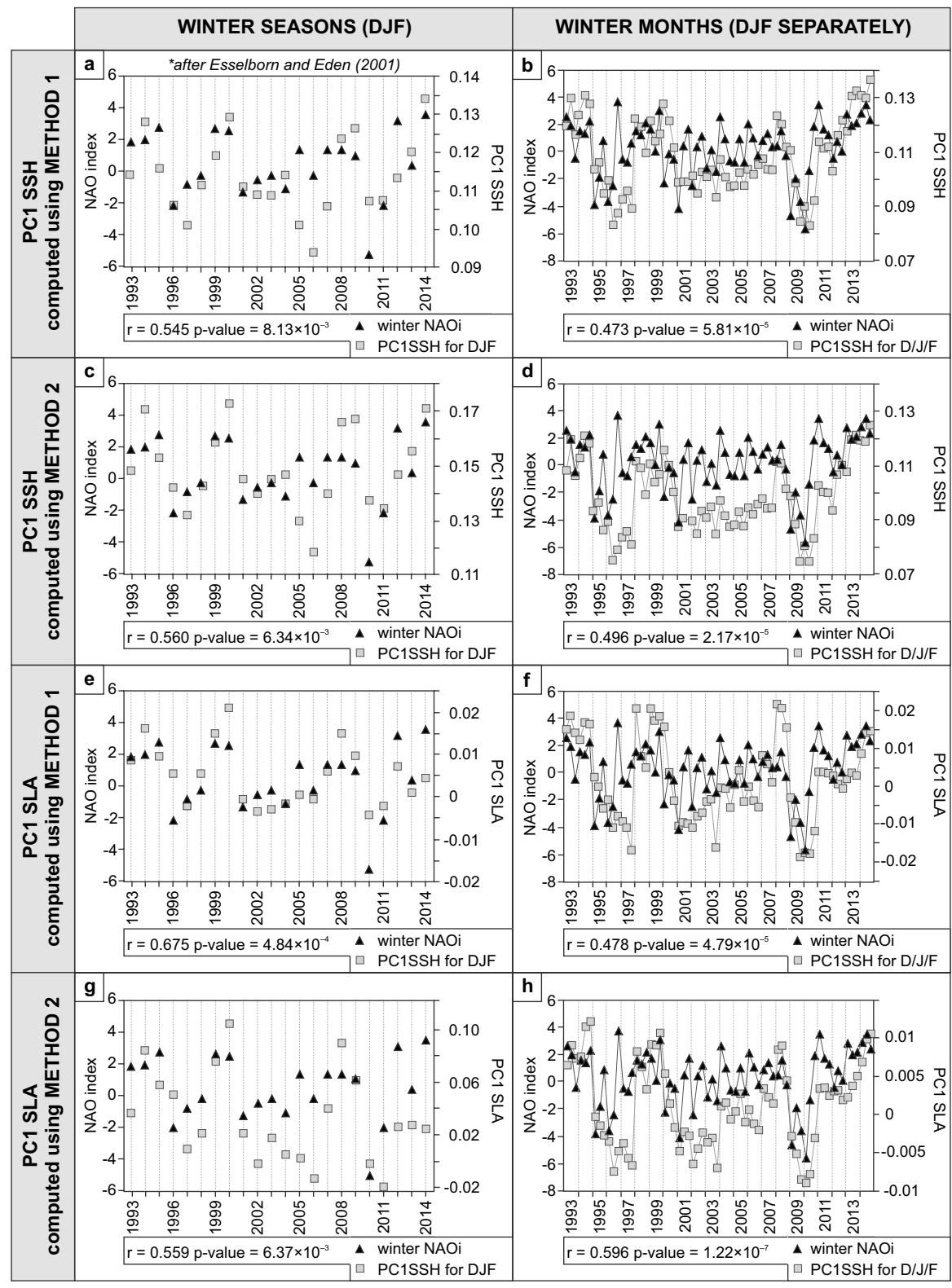

Fig. 3 Scheme presenting relationship between principal components of winter seasons (left column) and winter months (right column) of SSH (graphs a-d) and SLA (graphs e-h) observed data computed using method 1 and 2 (alternating rows) values of PC1s are presented as grey squares with black outline, values of NAOi are presented as black triangles. On the bottom of each graph, value of Pearson's correlation coefficient ( $r$ ) with statistical significance ( $p$-value) are presented 


\subsection{PC1 of SLA/SSH and NAOi}

The relationships between PC1 of SSH/SLA and winter NAOi are presented in Fig. 3. For each graph we present the value of Pearson's correlation coefficient $(r)$ with its statistical significance ( $p$-value). In the literature, a general appreciation for the level of correlation may include the following values: $0-0.09$ indicates no correlation, $0.1-0.3$ indicates a small correlation, 0.3-0.5 indicates a medium correlation, and 0.5-1 indicates a large correlation (e.g. Cohen 1988). When interpreting small correlations it is worth referring to the paper by Kozak et al. (2012) who argue that "low value of the correlation coefficient can represent incredibly strong association, while a high value can still represent weak correlation" and recommend the analysis of the context of the association.

In their study, Esselborn and Eden (2001) performed the analysis on short seasonal SSH time series using "method 1" of preparing dataset for PCA. The results of similar calculations, but using much longer time series, are shown in Fig. 3a. Their version based on monthly data is presented in graph " $b$ ". The corresponding analysis performed using "method 2" gives higher values of Pearson's correlation coefficient. The strongest correlation $(r=0.56)$ appears between DJF Hurrel NAOi and PC1SSH for DJF season (graph "c"). This confirms that there exists the strong relationship between SSH and NAOi, which can be used in the process of forecasting NAOi. The Prognocean Plus system produces predictions of SLA, therefore we conducted the same experiment with SLA data (Fig. 3e-h). The correlation coefficient between NAOi and PC1SLA in all cases is even higher than between NAOi and PC1SSH. The highest correlation value $(r=0.68)$ occurred between winter seasonal NAOi and PC1SLA for DJF season.

\subsection{Seasonal forecasts}

Using two regression models described in Sect. 3.4 which utilize PH+AR-based SLA predictions, we produced four seasonal prognoses of winter Hurrell NAOi. They are presented in rows of Fig. 4. In order to keep the calibration period long enough (at least 20 years), the first NAOi forecast is issued into the DJF season 2013/2014 (graphs "a" and "b"), while the last available prediction is for the DJF season 2016/2017 (graphs "g" and "h"). Each graph consists of black solid line reflecting values of the observed NAOi, solid grey (approach 1) and dark grey (approach 2) lines which are NAOi reconstructions from two regression models. Dashed lines and squares with the greyness intensity corresponding to the models indicate values of predicted DJF NAOi. Because of the stepwise recalibration of each model, every time when forecast is produced, these parts of graphs are different as the calibration dataset extends. The model recalibration shows that both models respond properly to changes of NAOi. The presented statistics (Table 1) show that the values of Pearson's correlation coefficient fall around 0.5, and the values of MAE or RMSE statistics fluctuate around 1.5. The empirically-corrected regression model (Eq. 4) reveals better performance and, because of the same variance as NAOi time series, it better reflects the amplitudes of NAOi changes.

Although Fig. 4 focuses on the PH+AR model only (it has the smallest misfit according to the conducted performance analysis), the skills of the remaining two deterministicstochastic models (PH+TAR and PH+MAR) are juxtaposed in Table 1. It is apparent from the table that choice of the SLA prediction model from those available in the Prognocean Plus system has no impact on the performance of NAOi forecasts. Higher correlations are 


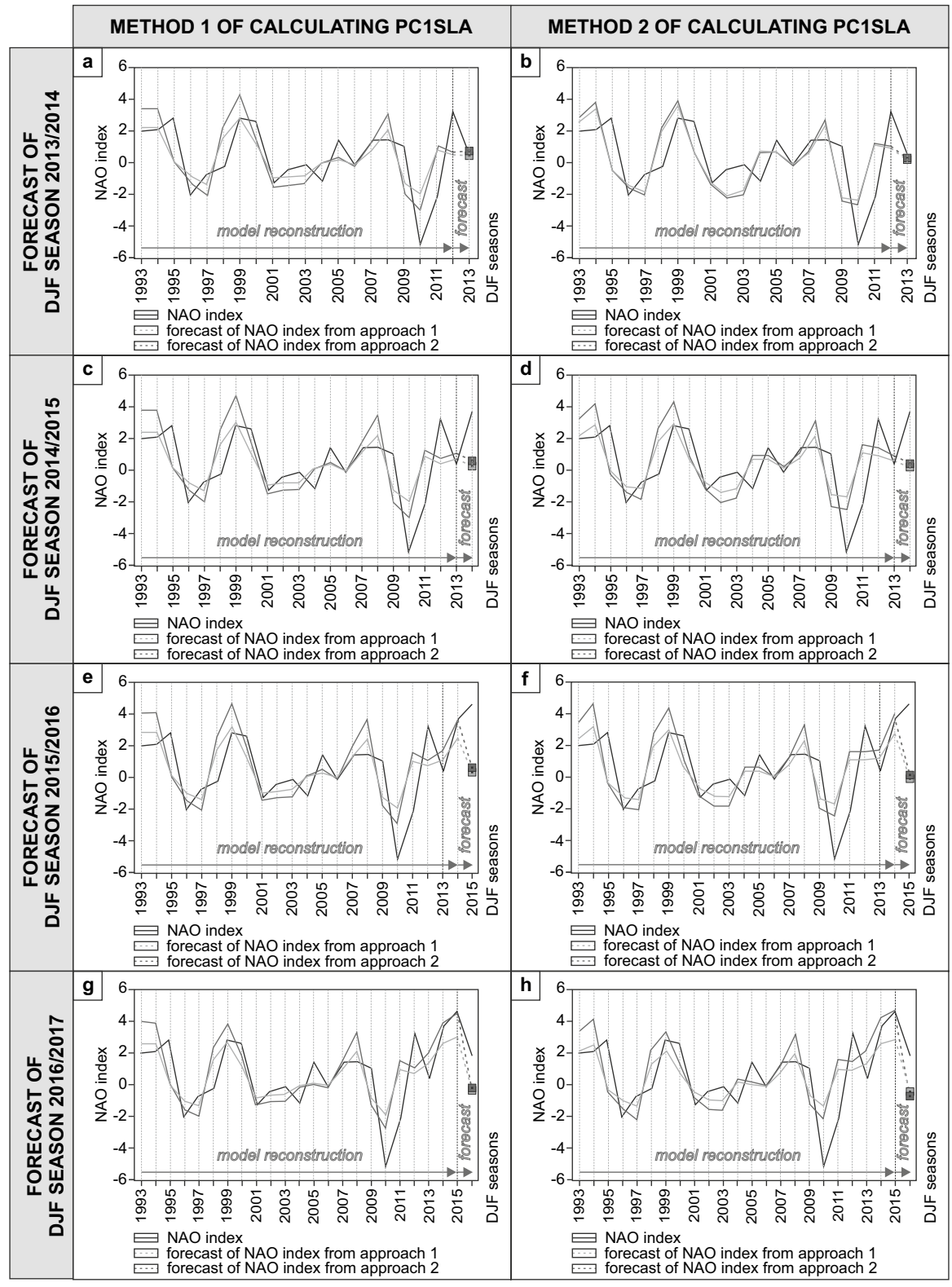

Fig. 4 Set of graphs presenting performance of two regression models in reconstructing and predicting winter seasonal Hurrell NAOi. In left column all regression models are based on the PC1SLA obtained using method 1, results using method 2 are in the right column. Each row shows results of reconstruction and prediction of one DJF season, where first row is forecasting Hurrell NAOi for winter season 2013/2014 and the last one-2016/2017. Observed NAOi is presented as solid black line. Reconstruction of NAOi using approach 1 (first regression model without correction) is an solid grey line, dark grey solid line is a performance of approach 1 (second regression model with correction). Predicted values of NAOi for each winter season are indicated as an filled square with black outline and marked centroid of the figure, joined by dashed-line. Fill of the square correspond to the line colour assigned to the forecasting approach 


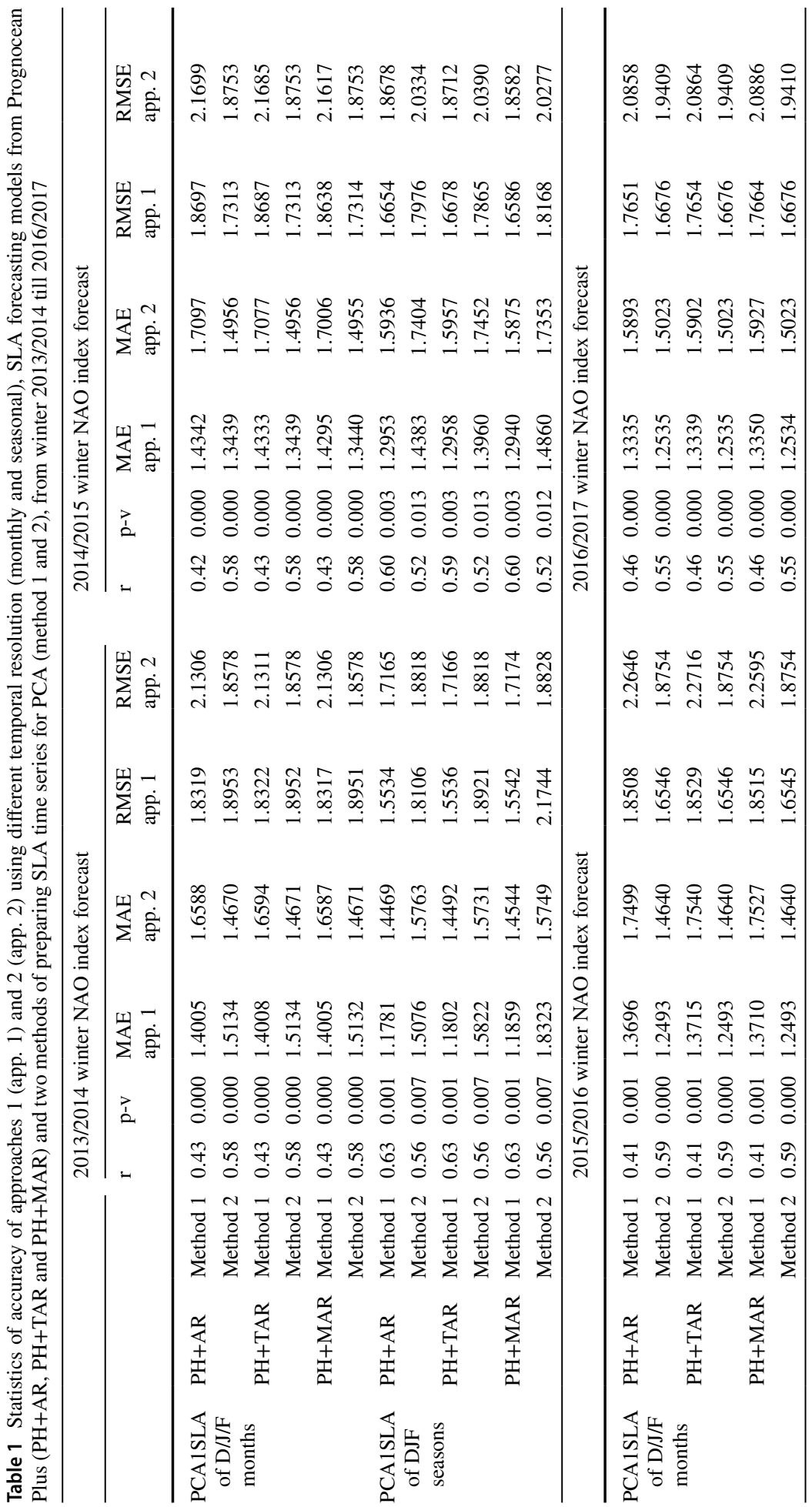




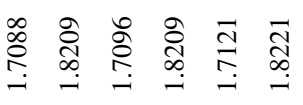

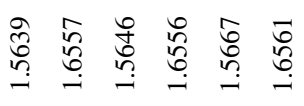

क

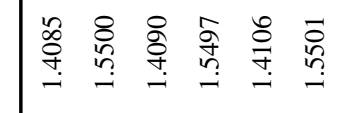

.

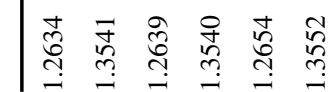

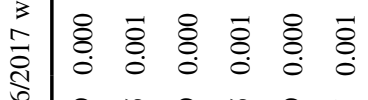

糵

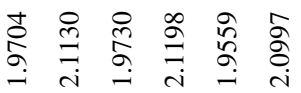

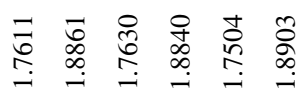

$\overrightarrow{\mathrm{g}}$

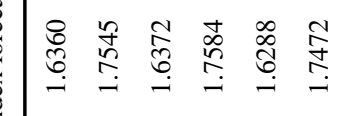

安

文

苦

望

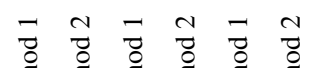

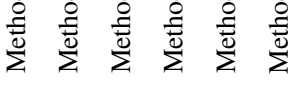

兽

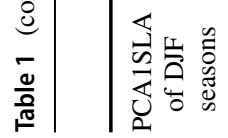




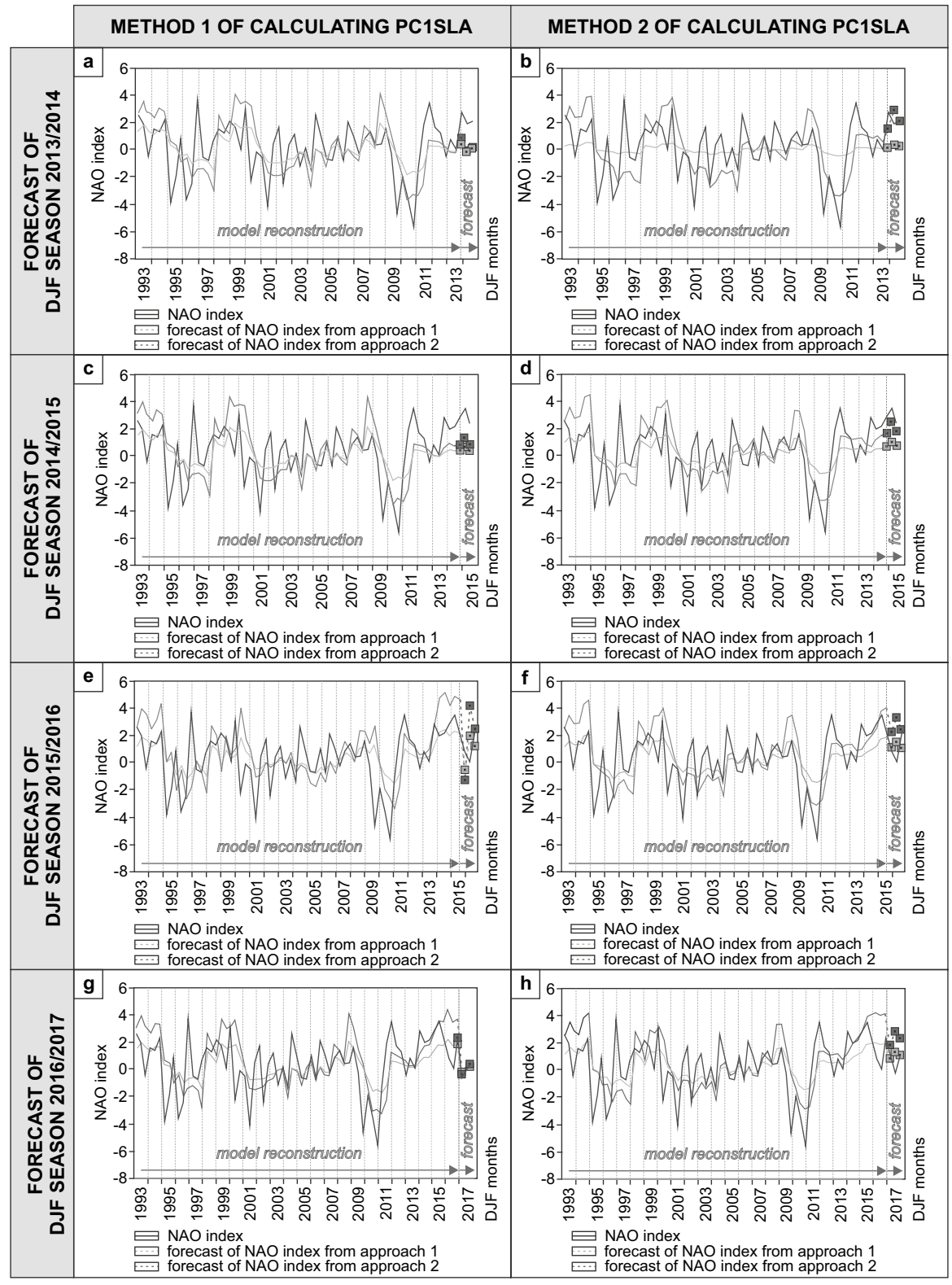

Fig. 5 Set of graphs presenting performance of two regression models in reconstructing and predicting winter monthly Hurrell NAOi. In left column all regression models are based on the PC1SLA obtained using method 1, results using method 2 are in the right column. Each row shows results of reconstruction and prediction of $\mathrm{D} / \mathrm{J} / \mathrm{F}$ months, where first row is forecasting Hurrell NAOi for winter months 2013/2014 and the last one-2016/2017. Observed NAOi is presented as solid black line. Reconstruction of NAOi using approach 1 (first regression model without correction) is an solid grey line, dark grey solid line is a performance of approach 1 (second regression model with correction). Predicted values of NAOi for each winter month are indicated as an filled square with black outline and marked centroid of the figure, joined by dashed-line. Fill of the square and colour of the dashed-lines correspond to the solid line colour assigned to the forecasting approach 


\section{SCATTER PLOT OF FIG.5B}

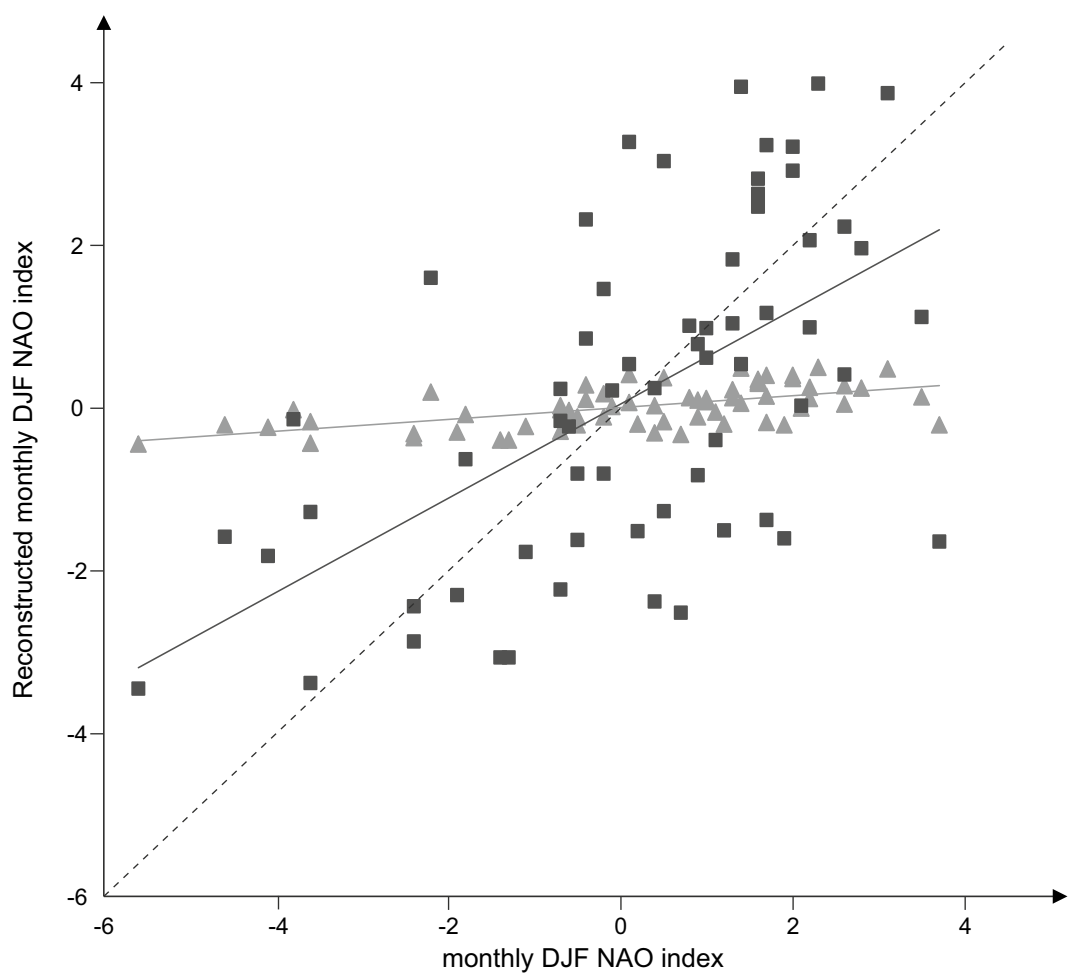

- reconstruction of NAO index from approach $1 \&$ NAO index

$\Delta$ reconstruction of NAO index from approach 2 \& NAO index

trendline of reconstruction of NAO index from approach 1 \& NAO index

trendline of reconstruction of NAO index from approach 2 \& NAO index

trendline of perfect reconstruction of NAO index \& NAO index

Fig. 6 Scatter plot of the case presented in Fig. 5b. Gray triangles represent corresponding values of reconstructed and predicted values of NAOi obtained from approach 1 (before correction) and observed NAOi, where dark grey squares indicate corresponding values of reconstructed and predicted values of NAOi obtained from approach 2 (after correction) and observed NAOi. Based on the corresponding values, solid lines representing trend lines are drawn. Dashed line indicates the ideal relationship between predicted or reconstructed values of NAOi and observed ones. Correlation coefficient $r=0.578$ for both approaches (scaling factor does not change $r$ )

found for "method 1" (in all variants), but at the same time prediction errors are similar or worse than in case of predicting winter months of NAOi. The PH+AR model reveals the lowest values of MAE and RMSE (the lowest values of these statistics are 1.18 and 1.55, respectively, for method 1, approach 1, season 2013/2014). However, it should be clearly noted that all values of prediction performance statistics are very similar. They are often non-recognizable, with differences occurring at the 4 th or 5 th decimal place. 


\subsection{Monthly forecasts}

We carried out a similar exercise, based on monthly data. In this setup, NAOi for three individual winter months is predicted. The results are presented in Fig. 5, the structure of which corresponds to Fig. 4.

The empirically-corrected regression model (Eq. 4) resolves the amplitude of NAOi better than the uncorrected model. Forecasts issued into D/J/F months for winter seasons 2015/2016 and 2016/2017 are accurate, with the NAOi amplitude correctly resolved. The usefulness of the empirical correction is well seen in Fig. 5b, where the corrected prediction curves accurately hit the true NAOi variability (predicted values correctly fitted the fluctuations in NAOi values, with absolute error smaller than 0.7). To convince the reader why the empirical correction was needed, the authors prepared Fig. 6 where the scatter plot of the mentioned case from Fig. 5b is presented. The amplitudes of the uncorrected NAOi changes determined through the reconstruction and prediction vary between -0.5 and 0.5 (gray rectangles), while the corrected ones (dark gray squares) are between -4 and 4 which much better reflects the real NAOi variability ( -5.5 to 4$)$.

Table 1 shows that for monthly predictions of NAOi, the use of "method 2" leads to the highest correlation coefficient values which exceed 0.59 (winter season 2015/2016). Based on the prediction errors, "method 2" is found to produce the most accurate forecasts of NAOi for D/J/F months in winter 2015/2016. In this exercise, 69 values of PCA1 and NAOi are used.

\subsection{Discussion}

It is known that correlations between NAOi and its short-term predictions are very high, i.e. $\geq 0.8$ up to 6-7 days into the future (Johansson 2007; Vitart 2014). They decrease to approximately 0.35 when lead time increases to 15 days (Johansson 2007).

Although our validation of monthly and seasonal forecasts, due to data availability, is limited to four winters $(2013 / 2014,2014 / 2015,2015 / 2016,2016 / 2017)$, we believe that the numerical exercise serves as a feasibility study to confirm the usefulness of the new methodical approach presented in this paper. Our method uses altimetric sea level change of northern Atlantic Ocean as a predictor of NAOi, and it is fundamentally different from the work of Saunders and Qian (2002) who employed SST variability to forecast NAOi. Even though the statistical robustness of our NAOi prediction validation is much worse than the robustness of the results published by Saunders and Qian (2002)-i.e. 20 years for comparing the reconstructed models with true data and 4 winters for comparing true data with predictions (our study) versus 51 years of cross-validation and 15 winters for comparing predictions with independent forecasts (Saunders and Qian 2002) - certain findings are similar. The two studies aim to anticipate NAOi in the 3-month DJF seasons. In the SSTbased NAOi prediction experiment, correlations were found to vary between 0.47 and 0.63 for the cross-validation period (51 years), while in our SLA-based NAOi prediction exercise correlations between true and reconstructed NAOi (20 years of calibration with stepwise extension by one year) were equal to $0.51-0.69$. Thus, SST- and SLA-based NAOi predictions have comparable skills.

Similarly, Saunders et al. (2003) obtained comparable correlations of $0.60-0.62$ in numerical hindcast experiments for intervals 1972-2001 and 1987-2001. Also, Johansson (2007) found that statistically significant correlations between monthly NAOi predictions and data vary from 0.36 to 0.63 , depending on month. Lower and often insignificant 
correlations (max 0.42) were found for seasonal predictions (Johansson 2007). For longer lead times (year-to-year) Kim et al. (2012) obtained much lower correlations (approx. 0.2), while Fan et al. (2016) presented slightly higher values (approx. 0.38-0.53). The recently developed statistical method by Wang et al. (2017) uses the multiple linear regression to forecast the NAO variability, with SST, $70 \mathrm{hPa}$ geopotential height and sea ice concentration as main predictors. The authors reported high correlations between data and NAO predictions. Also, high correlations, even exceeding 0.8 for selected cases, were obtained by Dobrynin et al. (2018) who used the dynamical ensemble approach.

The performance of our NAOi predictions is either controlled by the relationship between PC1SLA and NAOi, described by Esselborn and Eden (2001), or driven by the skills of the SLA predictions issued by the Prognocean Plus system (Świerczyńska et al. 2016). Figure 3 shows that our PC1SSH-NAOi analysis for 1993-2014 leads to findings which are similar to what Esselborn and Eden (2001) discovered. It is also apparent from Fig. 3 that correlations between PC1SLA and NAOi are higher than correlations PC1SSH-NAOi.

Our approach is purely statistical, since both the relationship borrowed from Esselborn and Eden (2001) and three models implemented in the Prognocean Plus system are empirical. There are other attempts to build such statistical prediction schemes to anticipate NAOi variability. For instance, Eshel (2003) focused on the Pacific-Atlantic teleconnection and built long-term 15-month NAOi predictions using sea level pressure, not only in northern Atlantic, but in particular in northern Pacific. The correlations between one-year NAOi predictions and observations were found to be approximately equal to 0.45 for 1925-2002 cross-validation experiment.

It is rather difficult to compare the skills of our predictions of NAOi with the corresponding forecasts based on other models run by different centres. For instance, the historical ECMWF prognoses are not archived (e-mail communication dated 01/08/2018), while the fortnight ensemble predictions computed by NOAA CPC are publically available solely as graphical plots without access to historical forecasts (www.cpc.ncep.noaa.gov/produ cts/precip/CWlink/pna/nao.shtml, access date: 09/08/2018). The comparison of prediction errors and skill measures must therefore be limited to published work in which different timespans are employed.

\section{Conclusions}

We developed a new method for forecasting winter Hurrell NAOi based solely on SLA predictions calculated by the Prognocean Plus system. Using the procedure proposed by Esselborn and Eden (2001) we demonstrated a significant relationship between SLA data, aggregated seasonally and monthly, and seasonal and monthly winter Hurrell NAOi (Pearson's correlation coefficient was equal to 0.69 and 0.59 , respectively). Forecasts of NAOi included winter season from 2013/2014 to 2016/2017 (four seasonal and four 3-monthly predictions).

The main finding of this paper is that it is possible to produce long-term (up to 3-months) predictions of NAOi based solely on SLAs. The study shows that using predictions of SLA from the Prognocean Plus system we are able to anticipate next values of winter NAOi with prediction errors of MAE and RMSE not exceeding 1.5 and 1.9, respectively. The key findings are the following: 
- forecast accuracy using regression models is satisfying, and the best performance was achieved using SLA forecasts from $\mathrm{PH}+\mathrm{AR}$ model implemented in the Prognocean Plus system,

- differences between performance statistics indicate that the choice of SLA forecasts model has less impact than the choice of method for preparing SLA time series for PCA,

- approach 1 of predicting NAOi fails to resolve NAOi amplitudes,

- approach 2 (empirically-corrected model outputs), properly resolves NAOi amplitudes,

- the calibration (reconstruction) of approaches 1 and 2 is characterized by high agreement with observations, while the predictions based on the reconstructions reveal only medium or low agreement with observations.

Acknowledgements The research was financed by the National Science Centre of Poland in frame of the research Project No. 2016/21/N/ST10/03231. The Prognocean Plus system was designed in frame of the project "New generation domain-specific services in the PL-Grid Infrastructure for Polish Science", No. POIG.02.03.00-12-138/13, founded by the European Regional Development Fund as part of the Innovative Economy. The authors would like to thank Copernicus Marine and Environment Monitoring Service for fruitful cooperation and courtesy in providing necessary data.

Open Access This article is licensed under a Creative Commons Attribution 4.0 International License, which permits use, sharing, adaptation, distribution and reproduction in any medium or format, as long as you give appropriate credit to the original author(s) and the source, provide a link to the Creative Commons licence, and indicate if changes were made. The images or other third party material in this article are included in the article's Creative Commons licence, unless indicated otherwise in a credit line to the material. If material is not included in the article's Creative Commons licence and your intended use is not permitted by statutory regulation or exceeds the permitted use, you will need to obtain permission directly from the copyright holder. To view a copy of this licence, visit http://creativecommons.org/licenses/by/4.0/.

\section{References}

Akaike H (1971) Autoregressive model fitting for control. Ann Inst Stat Math 23:163-180

Al-Karkhi AFM, Alqaraghuli WAA (2019) Applied statistics for environmental science with R. Elsevier, Amsterdam

Barnston AG, Livezey RE (1987) Classification, seasonality and persistence of low-frequency atmospheric circulation patterns. Mon Weather Rev 115(6):1083-1126

Bell GD, Chelliah M (2006) Leading tropical modes associated with interannual and multidecadal fluctuations in North Atlantic hurricane activity. J Clim 19(4):590-612

Benedict JJ, Sukyoung L, Feldstein SB (2004) Synoptic view of the North Atlantic oscillation. J Atmos Sci 61(2):121-144

Bjerknes J (1964) Atlantic air-sea interaction. Adv Geophys 10:1-82

Brockwell PJ, Davis RA (1996) Introduction to time series and forecasting. Springer, New York

Brockwell PJ, Davis RA (2002) Introduction to time series and forecasting. Springer, New York

Cabanes C, Thierry H, Colin de Verdiere A (2006) Contributions of wind forcing and surface heating to interannual sea level variations in the Atlantic Ocean. J Phys Oceanol 36(9):1739-1750

Chandler R, Scott M (2011) Statistical methods for trend detection and analysis in the environmental sciences. Wiley

Chen X, Dangendorf S, Narayan N, O’Driscoll K, Tsimplis MN, Su J, Mayer B, Pohlmann T (2014) On sea level change in the North Sea influanced by the North Atlantic Oscillation: local and remote steric effects. Estuar Coast Shelf Sci 151(5):186-195

Clark AJ (2008) An introduction on the dynamics of El Niño \& the Southern Oscillation. Elsevier Academic Press

Cohen J (1988) Statistical power analysis for the behavioral sciences, 2nd edn. Lawrence Erlbaum Associates, Mahwah 
Cromwell D (2006) Temporal and spatial characteristics of sea surface height variability in the North Atlantic Ocean. Ocean Sci 2:147-159

Cryer JD, Chan K-S (2008) Time series analysis with applications in R. Springer, New York

Czaja A, Frankignoul C (1999) Influence of the North Atlantic SST on the atmospheric circulation. Geophys Res Lett 26:2969-2972

Deser C, Blackon ML (1993) Surface climate variations over the North Atlantic Ocean during winter: 1900-1989. J Clim 6(9):1743-1753

Dobrynin M, Domeisen DIV, Müller WA, Bell L, Brune S, Bunzel F et al (2018) Improved teleconnectionbased dynamical seasonal predictions of boreal winter. Geophys Res Lett 45:3605-3614

Ducet N, Le Traon PY, Gauzelin P (1999) Response of the Black Sea mean level to atmospheric pressure and wind forcing. J Mar Syst 22:311-327

Eshel G (2003) Forecasting the North Atlantic Oscillation using North Pacific surface pressure. Mon Weather Rev 131(5):1018-1025

Esselborn S, Eden C (2001) Sea surface height changes in the North Atlantic Ocean related to the North Atlantic Oscillations. Geophys Res Lett 28:3473-3476

Fan K, Tian B, Wang H (2016) New approaches for the skillful prediction of the winter North Atlantic Oscillation based on coupled dynamic climate models. Int J Climatol 36(1):82-94

Feistel R, Nausch G, Wasmund N (eds) (2008) State and evolution of the Baltic Sea, 1952-2005: a detailed 50-year survey of meteorology and climate, physics, chemistry, and marine evnironment. Wiley, Hoboken

Feldstein SB (2003) The dynamics of NAO teleconnection pattern growth and decay. Q J R Meteorol Soc 129:901-924

Garrett CJR (1983) Variable sea level and strait flows in the Mediterranean: a theoretical study of the response to meteorological forcing. Oceanol Acta 6(1):79-87

Hurrell J \& National Center for Atmospheric Research Staff (eds) The climate data guide: Hurrell North Atlantic Oscillation (NAO) Index (station-based). https://climatedataguide.ucar.edu/climate-data/hurre 1l-north-atlantic-oscillation-nao-index-station-based. Accessed version was last modified on 7 Nov 2017

Hurrell JW, Kushnir Y, Ottersen G, Visbeck M (2003) An overview of the North Atlantic Oscillation. In: Hurrell JW, Kushnir Y, Ottersen, G, Visbeck M (eds) The North Atlantic Oscillation: climatic significance and environmental impact. American Geophysical Union, Geophysical Monograph, vol 134, pp $1-36$

Hurrell JW (1995) Decadal trends in the North Atlantic Oscillation: regional temperatures and precipitation. Science 269(5224):676-679

Iglesias I, Lorenzo MN, Lazáro C, Fernandes MJ, Bastos L (2017) Sea level anomaly in the North Atlantic and seas around Europe: long-term variability and response to North Atlantic teleconnection patterns. Sci Total Environ 609:861-874

IPCC (2007) Climate Change (2007) The physical science basis. Contribution of Working Group I to the Fourth Assessment Report of the Intergovermental Panel on Climate Change. Report edited by: Solomon S, Qin D, Manning M, Chen Z, Marquis M, Averyt KB, Tignor M, Miller HL, Cambridge University Press, Cambridge, United Kingdom and New York, USA

Johansson $\AA$ (2007) Prediction skill of the NAO and PNA from daily to seasonal time scales. J Clim 20(10):1957-1975

Jolliffe IT, Cadima J (2016) Principal component analysis: a review and recent developments. Philos Trans R Soc A Math Phys Eng Sci 374:20150202

Kim HM, Webster PJ, Curry JA (2012) Seasonal prediction skill of ECMWF system 4 and NCEP CFSv2 retrospective forecast for the Northern Hemisphere Winter. Clim Dyn 39(12):2957-2973

Kosek W (2001) Long-term and short period global sea level changes from TOPEX/Poseidon altimetry. Artif Satell 36:71-84

Kosek W, Niedzielski T, Popiński W, Zbylut M, Wnęk A (2016) Variable seasonal and subseasonal oscillations in sea level anomaly data and their impact on sea level prediction accuracy. In: Sneeuw N, Novák P, Crespi M, Sansò F (eds) VIII Hotine-Marussi symposium on mathematical geodesy, International Association of geodesy symposia, vol 142. Springer, pp 47-50

Kozak M, Krzanowski W, Tartanus M (2012) Use of the correlation coefficient in agricultural sciences: problems, pitfalls and how to deal with them. Anais da Academia Brasileira de Ciências 84(4):1147-1156

Lardies J (1996) Analysis of a multivariate autoregressive process. Mech Syst Signal Process 10:747-761

Lozier MS, Leadbetter S, Williams RG, Roussenov V, Reed MS, Moore NJ (2008) The spatial pattern and mechanisms of heat-content change in the North Atlantic. Science 319(5864):800-803 
Marshall J, Schott F (1999) Open-ocean convection: observations, theory, and models. Rev Geophys 37(1):1-64

Mathers EL, Woodworth PL (2001) Departures from the local inverse barometer model observed in altimeter and tide gauge data and in a global barotropic numerical model. J Geophys Res 106(C4):6957-6972

McPhaden MJ, Zebiak SE, Glantz MH (2006) ENSO as an integrating concept in Earth science. Science 314(5806):1740-1745

Moore JC, Grinsted A, Zwinger T, Jevrejeva S (2013) Semiempirical and process-based global sea level projections. Rev Geophys 51(3):484-522

Niedzielski T, Kosek W (2009) Forecasting sea level anomalies from TOPEX/Poseidon and Jason-1 satellite altimetry. J Geodesy 83:469-476

Niedzielski T, Kosek W (2011) Minimum time span of TOPEX/Poseidon, Jason-1 and Jason-2 global altimeter data to detect a significant trend and acceleration in sea level change. Adv Sp Res 47:1248-1255

Niedzielski T, Miziński B (2013) Automated system for near-real time modelling and prediction of altimeter-derived sea level anomalies. Comput Geosci 58:29-39

Olsen J, Anderson NJ, Knudsen MF (2012) Variability of the North Atlantic Oscillation over the past 5200 years. Nat Geosci 5(11):808-812

Peng S, Robinson WA, Hoerling MP (1997) The modeled atmospheric response to midlatitude SST anomalies and its dependence on background circulation states. J Clim 10(5):971-987

Pingree RD (2002) Ocean structure and climate (Eastern North Atlantic): in situ measurement and remote sensing (altimeter). J Mar Biol Assoc UK 82(5):681-707

Ponte R, Gaspar P (1999) Regional analysis of the inverted barometer effect over the global ocean using TOPEX/POSEIDON data and model results. J Geophys Res 104(C7):15587-15601

R Development Core Team (2008) A language and environment for statistical computing. R Foundation for Statistical Computing, Vienna, Austria. www.r-project.org. Accessed 23 June 2020

Ratcliffe RAS, Murray R (1970) New lag associations between North Atlantic sea temperature and European pressure applied to long-range weather forecasting. Q J R Meteorol Soc 96(408):226-246

Rodwell MJ, Folland CK (2003) Atlantic air-sea interaction and seasonal predictability. Q J R Meteorol Soc 128(538):1413-1443

Rodwell MJ, Rowell DP, Folland CK (1999) Oceanic forcing of the wintertime North Atlantic Oscillation and European climate. Nature 398:320-323

Rogers JC (1990) Patterns of low-frequency monthly sea level pressure variability (1899-1986) and associated wave cyclone frequencies. J Clim 3(12):1364-1379

Rogers JC, van Loon H (1979) The seesaw in winter temperatures between Greenland and northern Europe. Part II: some oceanic and atmospheric effects in middle and high latitudes. Mon Weather Rev 107(5):509-519

Sarachik ES, Cane MA (2010) The El Niño-Southern Oscillation phenomenon. Cambridge University Press, Cambridge, New York, Melbourne, Madrid, Cape Town, Singapore, Sao Paulo, Delhi, Dubai, Tokyo

Saunders MA, Qian B (2002) Seasonal predictability of the winter NAO from North Atlantic sea surface temperatures. Geophys Res Lett 29(22):6-1

Saunders MA, Qian B, Lloyd-Hughes B (2003) Summer snow extent heralding of the winter North Atlantic Oscillation. Geophys Res Lett 30(7):1378

Smith DG, Scaife AA, Eade R, Khight JR (2014) Seasonal to decadal prediction of the winter North Atlantic Oscillation: emerging capability and future prospects. Q J R Meteorol Soc 142(695):611-617

Stephenson DB, Pavan V, Bojariu R (2000) Is the North Atlantic Oscillation a random walk? Int J Climatol 20(1):1-18

Świerczyńska M, Miziński B, Niedzielski T (2016) Comparison of predictive skills offered by Prognocean, Prognocean Plus and MyOcean real-time sea level forecasting systems. Ocean Eng 113:44-56

Tapolczai K, Vasselon V, Bouchez A, Stenger-Kovács C, Padisák J, Rimet F (2018) The impact of OTU sequence similarity threshold on diatom-based bioassessment: a case study of the rivers of Mayotte (France, Indian Ocean). Ecol Evol 9:166-179

Van Loon H, Rogers JC (1978) The seesaw in winter temperatures between Greenland and northern Europe. Part I: general description. Mon Weather Rev 106(3):296-310

Venables WN, Ripley BD (2002) Modern applied statistics with S, 4th edn. [internet]. Springer, New York

Visbeck MH, Hurrell JW, Polvani L, Cullen HM (2001) The North Atlantic Oscillation: past, present, and future. Proc Natl Acad Sci 98(23):12876-12877

Vitart F (2004) Monthly forecasting at ECMWF. Mon Weather Rev 132:2761-2779

Vitart F (2014) Evolution of ECMWF sub-seasonal forecast skill scores. Q J R Meteorol Soc 140(683):1889-1899 
Wagner CA, Tai CK, Kuhn JM (1994) Improved $\mathrm{M}_{2}$ ocean tide from TOPEX/POSEIDON and Geosat altimetry. J Geophys Res 99(C12):24853-24865

Walker GT (1923) Correlations in seasonal variations of weather, VIII. A preliminary study of world weather I. Mem Indian Meteorol Dep 23:75-131

Walker GT (1924) Correlation in seasonal variations of weather. IX. A further study of world weather. Mem Indian Meteorol Dep 24(9):275-332

Walker GT, Bliss EW (1932) World weather V. Mem R Meteorol Soc 4(36):53-83

Wallace JM, Gutzler DS (1981) Teleconnections in the geopotential height field during the Northern Hemisphere winter. Monthly Weater Review 109:784-812

Wang L, Ting M, Kushner PJ (2017) A robust empirical seasonal prediction of winter NAO and surface climate. Sci Rep 7:279

Wanner H, Brönnimann D, Casty S, Gyalistras D, Luterbacher J, Schmutz C, Stephenson DB (2001) North Atlantic Oscillation-concepts and studies. Surv Geophys 22(4):231-381

Will AP, Kitaysky AS (2018) Variability in trophic level and habitat use in response to environmental forcing: isotopic niche dynamics of breeding seabirds in the southeastern Bering Sea. Mar Ecol Prog Ser 593:247-260

Woollings T, Franzke C, Hodson DLR, Dong B, Barnes EA, Raible CC, Pinto JG (2015) Contrasting interannual and multidecadal NAO variability. Clim Dyn 45(1-2):539-556

Wunsch C, Stammer D (1997) Atmospheric loading and the oceanic "inverted barometer" effect. Rev Geophys 35(1):79-107

Yeager S, Karspeck A, Danabasoglu G, Tribbia J, Teng H (2012) A decadal prediction case study: late twentieth-century North Atlantic Ocean heat content. J Clim 25(15):5173-5189 